\title{
Transbronchial Cryobiopsies for the Diagnosis of Diffuse Parenchymal Lung Diseases: Expert Statement from the Cryobiopsy Working Group on Safety and Utility and a Call for Standardization of the Procedure
}

\author{
Jürgen Hetzel ${ }^{\mathrm{a}}$ Fabien Maldonado $^{\mathrm{b}}$ Claudia Ravagliac ${ }^{\mathrm{c}}$ Athol U. Wells ${ }^{\mathrm{d}}$ Thomas V. Colby
} Sara Tomassettic Jay H. Ryu ${ }^{f}$ Oren Fruchter ${ }^{\mathrm{c}}$ Sara Piciucchi ${ }^{\text {h }}$ Alessandra Dubini ${ }^{i}$

Alberto Cavazza $^{j}$ Marco Chilosi $^{k}$ Nicola Sverzellatil Dominique Valeyre ${ }^{m}$ Dimitri Leduc $^{n}$

Simon L.F. Walsh ${ }^{\circ}$ Stefano Gasparini ${ }^{p}$ Martin Hetzel ${ }^{q} \quad$ Lars Hagmeyer $^{r}$ Maik Haentschel $^{a}$ Ralf Eberhardt $^{s}$ Kaid Darwiche ${ }^{t}$ Lonny B. Yarmus ${ }^{u}$ Alfonso Torrego ${ }^{v}$ Ganesh Krishnaw

Pallav L. Shah ${ }^{x}$ Jouke T. Annema ${ }^{y}$ Felix J.F. Herth ${ }^{s}$ Venerino Polettic, ${ }^{\mathrm{c}}$

a Department of Hematology, Oncology, Rheumatology, Immunology and Pulmonology, University of Tübingen,

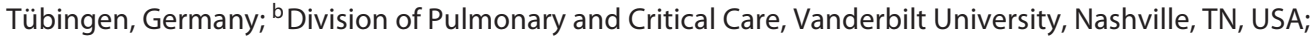
'Department of Diseases of the Thorax, Ospedale GB Morgagni, Forli, Italy; ${ }^{\mathrm{d} I n t e r s t i t i a l ~ L u n g ~ D i s e a s e ~ U n i t, ~ R o y a l ~}$ Brompton Hospital, London, UK; ${ }^{e}$ Department of Pathology, Mayo Clinic, Scottsdale, AZ, USA; ${ }^{\text {f Pulmonary and }}$ Critical Care Medicine, Mayo Clinic, Rochester, MN, USA; ${ }^{9}$ Pulmonary Division, Wolfson Medical Center and Tel Aviv University, Tel Aviv, Israel; ${ }^{h}$ Department of Radiology, Ospedale GB Morgagni, Forli, Italy; 'Department of

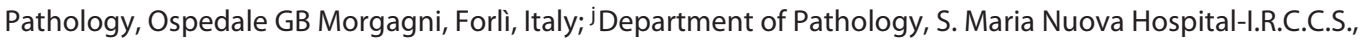
Reggio Emilia, Italy; ${ }^{k}$ Department of Pathology, Verona University, Verona, Italy; 'Division of Radiology, Department of Clinical Sciences, University of Parma, Parma, Italy; ${ }^{\mathrm{m}}$ Assistance Publique-Hôpitaux de Paris, Avicenne University Hospital, Bobigny, France; ' Department of Chest Medicine, Erasme University Hospital, Free University of Brussels, Brussels, Belgium; ${ }^{\circ}$ King's College Hospital Foundation Trust, London, UK; ${ }^{P}$ Department of Biomedical Sciences and Public Health, Università Politecnica delle Marche, and Pulmonary Diseases Unit, Department of Internal Medicine, Azienda Ospedaliero-Universitaria "Ospedali Riuniti", Ancona, Italy; ' Krankenhaus vom Roten Kreuz, Stuttgart, Germany; ${ }^{r}$ Clinic for Pneumology and Allergology, Center of Sleep Medicine and Respiratory Care, Bethanien

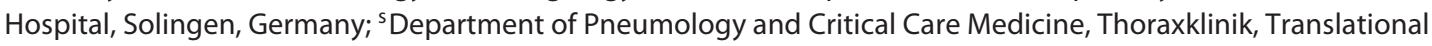
Lung Research Center Heidelberg, German Center for Lung Research (DZL), University of Heidelberg, Heidelberg, Germany; ${ }^{\text {t} D e p a r t m e n t ~ o f ~ I n t e r v e n t i o n a l ~ P u l m o n o l o g y, ~ R u h r l a n d k l i n i k, ~ U n i v e r s i t y ~ H o s p i t a l, ~ U n i v e r s i t y ~}$ Duisburg-Essen, Essen, Germany; ${ }^{u}$ Johns Hopkins University School of Medicine, Baltimore, MD, USA; vBronchoscopy Unit, Respiratory Department, University Hospital de la Santa Creu i Sant Pau, Barcelona, Spain; wDivision of Pulmonary, Critical Care, Allergy and Sleep Medicine, University of California, San Francisco, El Camino Hospital, Mountain View, CA, USA; ${ }^{x}$ The National Institute for Health Research, Respiratory Biomedical Research Unit, Royal Brompton and Harefield NHS Foundation Trust, and Imperial College, London, UK; ' Department of Respiratory Medicine, Academic Medical Center, Amsterdam, The Netherlands; ${ }^{2}$ Department of Respiratory Diseases and Allergology, Aarhus University Hospital, Aarhus, Denmark

J. Hetzel, F. Maldonado, C. Ravaglia, and V. Poletti contributed equally to this work. (c) 2018 S. Karger AG, Basel

E-Mail karger@karger.com

www.karger.com/res
Jürgen Hetzel

Department of Hematology, Oncology, Rheumatology, Immunology and Pulmonology University of Tübingen, Otfried-Müller-Str. 10

DE-72076 Tübingen (Germany)

E-Mail juergen.hetzel@med.uni-tuebingen.de

Venerino Poletti

Department of Diseases of the Thorax, Ospedale GB Morgagni

Via Carlo Forlanini, 34 - Pavilion Morgagni

IT-47100 Forlì (Italy)

E-Mail venerino.poletti@gmail.com 


\section{Keywords}

Transbronchial lung cryobiopsy · Diffuse parenchymal lung disease $\cdot$ Interstitial lung disease $\cdot$ Safety $\cdot$ Bronchoscopy

\section{Abstract}

Transbronchial cryobiopsies (TBCB) have recently been introduced as a promising and safer alternative to surgical lung biopsy in the diagnostic approach to diffuse parenchymal lung diseases (DPLD). Despite a substantial and expanding body of literature, the technique has not yet been standardized and its place in the diagnostic algorithm of DPLD remains to be defined. In part, this reflects concerns over the diagnostic yield and safety of the procedure, together with the rapid spread of the technique without competency and safety standards; furthermore, there is a substantial procedural variability among centers and interventional pulmonologists. We report this expert statement proposed during the third international conference on "Transbronchial Cryobiopsy in Diffuse Parenchymal Lung Disease" (Ravenna, October 27-28, 2016), which formulates evidence- and expertbased suggestions on the indications, contraindications, patient selection, and procedural aspects of the procedure. The following 5 domains were reviewed: (1) what is the role of TBCB in the diagnostic evaluation of DPLD: patient selection; (2) pathological considerations; (3) contraindications and safety considerations; (4) how should TBCB be performed and in what procedural environment; and (5) who should perform TBCB. Finally, the existence of white paper recommendations may also reassure local hospital credentialing committees tasked with endorsing an adoption of the technique.

(c) 2018 S. Karger AG, Basel

\section{Introduction}

Diffuse parenchymal lung diseases (DPLD) represent approximately $15 \%$ of consultations for the general pulmonologist [1]. While a broad spectrum of DPLD exists, approximately $30 \%$ of these patients have idiopathic pulmonary fibrosis (IPF), a progressive fibrotic disease with variable clinical course but, in general, poor survival [2]. The current approach to the diagnosis and management of DPLD includes a multidisciplinary discussion (MDD) undertaken by clinicians, radiologists, and pathologists [3]. Qualitatively and quantitatively adequate lung biopsies are essential contributors to the diagnosis when highresolution computed tomography (HRCT) findings as well as clinical and laboratory data are insufficient. His- torically, surgical lung biopsy (SLB) has been considered as the definitive means of obtaining adequate biopsy specimens. However, in many patients, the risk/benefit ratio of the procedure is unacceptable. Morbidity and mortality related to SLB are substantial, particularly in older subjects, in patients with significant comorbidities or severe respiratory impairment, and in cases with a final diagnosis of IPF $[4,5]$. This has major implications regarding IPF diagnosis. Recent data from large randomized controlled trials suggest that histological information is required in at least $30-40 \%$ of IPF patients in order to meet diagnostic criteria as suggested in the $2011 \mathrm{IPF}$ guidelines [6-8]. In the absence of SLB, the diagnosis of IPF is likely underestimated as HRCT findings definitive for usual interstitial pneumonia (UIP) are only present in about $50 \%$ of IPF cases. In these patients, a final diagnosis of "unclassifiable interstitial lung disease (ILD)" is associated with major management uncertainties.

The search for a minimally invasive alternative to SLB is motivated by the need to reduce the prevalence of "unclassifiable ILD," to reduce the complication rate associated with SLB and to offer opportunities to obtain representative specimens of lung tissue in a larger group of patients. Conventional forceps bronchoscopic biopsies are useful in bronchocentric or perilymphatic diseases, and in those with distinctive histopathological features that can be recognized even in small samples such as sarcoidosis, carcinomatous lymphangitis, and organizing pneumonia [9-11]. However, in diseases with heterogeneous histological patterns and in those with the main histological abnormalities located at the periphery of the secondary lobule, such as UIP, forceps biopsies are rarely sufficient to establish the diagnosis with confidence [12, 13]; the patchy fibrosis pattern is difficult to identify in these tiny specimens because of the crush artifacts frequently present [12]; therefore, its sensitivity in the diagnosis of the UIP pattern is very low $[12,14]$; when fibroblastic foci and honeycomb changes are identified, its specificity for the UIP pattern appears to be high $[12,13]$. The recent introduction of transbronchial cryobiopsies (TBCB) as a promising and safer alternative to SLB is generating considerable interest in the pulmonary community $[15,16]$. The indication for TBCB within the context of a MDD, vis-à-vis other diagnostic procedures, such as HRCT, conventional forceps biopsies, and SLB, remains to be defined. In addition, despite a substantial and expanding body of literature, TBCB technique has not yet been standardized, and techniques, reported diagnostic yields, and complications vary widely [17]. Recent reports have also highlighted, not unexpectedly, a greater compli- 
cation rate than initially estimated, which has unquestionably hindered adoption of the technique by ILD and bronchoscopy specialists $[18,19]$. The substantial procedural variability among centers and interventional pulmonologists and uncertainty on diagnostic yield complications on one hand [16, 20-33], and the promises of a potential useful and minimally invasive alternative to SLB on the other hand underscore the need of this expert statement.

\section{Methods}

During the third international conference on "Transbronchial Cryobiopsy in Diffuse Parenchymal Lung Disease" which took place on October 27-28, 2016, in Ravenna, specific concerns were raised by participants regarding the rapid spread of the technique in the absence of competency and safety standards. A working group was convened during the conference and tasked with reviewing the existing evidence and formulating, if possible, evidence- and expert-based suggestions on the indications, contraindications, patient selection, and procedural aspects of the procedure.

There are several reasons for such a document:

- $\quad$ TBCB is a promising alternative to SLB, but patient safety and diagnostic yield remain a concern, and a comprehensive review and discussion of the literature are presented.

- There is a general consensus among centers experienced with TBCB on the requisite equipment, personnel, indications, contraindications, risks, and training requirements for TBCB which may facilitate uniform practice and provide a guide for those wishing to introduce this technique.

- There is a need for standardization of TBCB procedures given the majority reported variability in diagnostic yield (50-100\%) and complications (rate of pneumothorax from $0 \%$ up to about 30\%) [34-36].

- The existence of expert recommendations may reassure local hospital credentialing committees tasked with endorsing an adoption of the technique.

This statement is built upon our previous systematic review, which was updated with new additions in the literature with suggestions from experienced users for the purpose of this position statement [34]. The systematic review of the literature was performed according to the guidelines developed by the Meta-analysis Of Observational Studies in Epidemiology (MOOSE) group [34, 37]. We searched Medline, Embase, Cochrane Central Register of Controlled Trials, and conference proceedings for all original articles on diagnostic yield and safety of TBCB for the diagnosis of DPLDs (i.e., suspected ILD, pulmonary infiltrates), for routine surveillance after lung transplantation or for research purpose, using a combination of free text and MESH/Emtree terms. The electronic search was supplemented by the gray literature and by handsearching the bibliography of relevant articles. We did not consider studies reporting data on TBCB for the diagnosis of peripheral or central lung lesions [34]. We considered weighing the evidence and providing perceived strengths of recommendations using the Grading of Recommendations Assessment, Development and Evaluation (GRADE), but after careful review of the lit- erature and consideration of the low level of evidence available, the working group decided to agree on general suggestions without formal individual grading of level of evidence and strength of recommendations. Accordingly, this document is restricted to expert suggestions based on low evidence.

The following 5 domains were considered:

1. What is the role of TBCB in the diagnostic evaluation of DPLD: patient selection

2. Histopathological considerations

3. Contraindications and safety considerations

4. How should TBCB be performed and in what procedural environment?

5. Who should perform TBCB?

\section{What Is the Role of TBCB in the Diagnostic Evaluation of DPLD: Patient Selection}

In general, the indications for TBCB for DPLD are the same as for SLB. Nonetheless, the clinical-radiological criteria used to select patients for biopsy may need to be re-assessed, given the availability of TBCB. For example, SLB is typically not indicated in subjects having HRCT images demonstrating a typical UIP pattern. However, the availability of TBCB and its lower morbidity compared to SLB could potentially broaden the indication for lung biopsy such as in DPLD patients with equivocal exposures or suspicion of an occult collagen vascular disease who may exhibit histopathological clues to alternative diagnoses (e.g., small granulomas, foci of organizing pneumonia, lymphoid follicles, pulmonary and pleural chronic inflammation) on cryobiopsy that might add weight to other diagnoses [30, 38, 39]. Therefore, ТВСB could sometimes be proposed in patients with a typical radiological UIP pattern, with the aim of collecting more definitive data suggesting occult exposures or collagen vascular diseases.

There is a substantial mortality rate after SLB, which is even higher in patients with underlying morbidities or evidence of disease progression $[4,5]$. The acute exacerbation after SLB is hypothesized to be related to barotrauma during single lung ventilation and perhaps oxygen toxicity manifesting first in the lung not submitted to biopsy. The analysis of data already published on TBCB documents 7 deaths within a month after the procedure: 1 patient died from respiratory failure after TBCB due to lymphangitic carcinomatosis, 1 from acute myocardial infarction manifesting weeks later, 1 from pulmonary edema from newly diagnosed severe aortic stenosis, 1 with organizing pneumonia and who was on palliative care, 1 from pulmonary embolism, 2 patients from acute exacerbation of IPF [27, 40-42] (in both cases of death 
from acute exacerbation, diffuse alveolar damage was the histological background and the complication developed after significant procedural complications such as tension pneumothorax and subsequent ventilation with high positive airway pressures or severe bleeding). A more recent case of acute exacerbation of ILD as a complication of TBCB has been reported in a patient with nonspecific interstitial pneumonitis (although this case report does not describe the TLCB technique specifically, analysis of histology, description of HRCT features, and clinical information documenting the presence of a stable disease or rapid progressive deterioration before the TBCB) [43]. The risk of acute exacerbation needs to be assessed before the procedure, particularly in case of recent worsening [4, 5]. Recent onset of patchy ground glass areas on HRCT scan, functional deterioration and/or increased dyspnea on exertion in the last month and/or high levels of inflammatory or more specific markers (KL-6) could be predictors of a high acute exacerbation risk $[44,45]$.

In patients with chronic fibrosing DPLDs, low pulmonary function values have a prognostic impact and are associated with a higher rate of significant complications after SLB [46]. In this context, SLB has a disadvantageous risk/benefit ratio. The clinical value of TBCB in this setting is not yet known. In other DPLDs, patients without an overt fibrosing component, but with an acute or subacute behavior, including those with a major reduction in lung function, a definite diagnosis by TBCB can be achieved. In fact, cases with a final morphological diagnosis of organizing pneumonia, nonspecific interstitial pneumonia, diffuse alveolar damage, capillaritis, intravascular lymphoma, infections, and acute/subacute rejection have been reported; TBCB may also be helpful in patients with suspected hypersensitivity pneumonitis and equivocal exposure [25, 47-49].

The introduction of TBCB as a minimally invasive technique and as a suitable minimally invasive alternative to SLB for the diagnosis of DPLD could transform the clinical approach to these patients. Obtaining representative and diagnostic lung tissue samples with less risk of morbidity and mortality could expand indications and augment the possibility of adding morphological information to data already acquired by clinical investigation, laboratory tests, and HRCT scan [38].

\section{Key Points}

a. Patients with DPLD without a diagnosis after integration of clinical profile, laboratory tests, and HRCT features could be submitted to TBCB instead of SLB in centers with an established experience in the MDD and TBCB. b. A typical UIP pattern on HRCT is generally sufficient for diagnosis and precludes SLB but may not represent an absolute contraindication to TBCB (as may happen even considering SLB), if there is a clinical reason to consider histological evaluation.

c. Patients with an acute or subacute lung disease which is not rapidly progressing with a low probability of having acute exacerbation of IPF might benefit from TBCB.

\section{Pathological Considerations}

The pathological approach to TBCB and to other lung biopsy specimens is similar. In some cases, a specific histological diagnosis can be made (e.g., PLCH, malignancy) whereas in others, a pattern of injury is identified (e.g., UIP) that allows a confident multidisciplinary diagnosis with the integration of clinical and HRCT findings. The same histopathological patterns that require a larger specimen for recognition (e.g., UIP) may still be identified on TBCB albeit with a lower frequency (75-80 vs. $>95 \%$ ) than with SLB. Furthermore, while the smaller size of the specimens may initially lead to some hesitation and a lower confidence in histological diagnosis from pathologists evaluating TBCB in comparison to SLB, one should still attempt to label patterns just as one does with SLB and recognize that input from MDD will keep the pathology interpretation in context. About $20 \%$ of cryobiopsies will be nondiagnostic; the reasons may include inadequate lung tissue (i.e., the specimen is predominantly airway wall), normal lung tissue (sampling error), or lung tissue with very minor and nonspecific pathology.

The optimal lung biopsy specimen size in the diagnosis of DPLD has not been established. However, Casoni et al. [27] showed that the area of samples strongly correlates with the diagnostic yield. In that study, the mean area of the samples was $41.99 \pm 14.43 \mathrm{~mm}^{2}$ in the group that received a morphological diagnosis and $28.43 \pm 11.66 \mathrm{~mm}^{2}$ in cases without a morphological diagnosis. $40 \mathrm{~mm}^{2}$ represents 2 biopsy specimens, each $5 \times 4 \mathrm{~mm}$, and anecdotally pathologists suggest that adequate specimens should measure at least $5 \mathrm{~mm}$ in diameter since that corresponds to the size of the full field seen with a $4 \times$ objective on many microscopes. Such a field size allows pattern recognition in many cases [47].

The processing of TBCB specimens is similar to the other lung biopsies: fixation in formalin, paraffin embedding, and formation of hematoxylin and eosin slides (at least 2 levels is recommended, and any initial special 
Table 1. Comparison between transbronchial forceps biopsy, transbronchial cryobiopsy, and surgical lung biopsy

\begin{tabular}{|c|c|c|c|c|}
\hline First author [Ref.], year & Diagnostic yield & Pneumothorax & $\begin{array}{l}\text { Serious } \\
\text { bleeding }\end{array}$ & $\begin{array}{l}\text { Mortality due to } \mathrm{AE} \\
\text { (in } 30 \text { days) }\end{array}$ \\
\hline Cryobiopsy & $>50.6 \%$ & $0-26 \%$ & $0-42 \%$ & $<2 \%$ \\
\hline Babiak [16], 2009 & $39 / 41(94 \%)$ & $2(4.8 \%)$ & 0 & - \\
\hline Kropski [22], 2013 & $20 / 25(80 \%)$ & 0 & 0 & - \\
\hline Fruchter [24], 2013 & $40 / 40(100 \%)$ & 0 & 0 & - \\
\hline Yarmus [23], 2013 & - & $1(4.8 \%)$ & 0 & 0 \\
\hline Pajares [28], 2014 & $39 / 77(50.6 \%)$ & $3(8 \%)$ & 0 & - \\
\hline Fruchter [26], 2014 & $51 / 75(68 \%)$ & $2(2.6 \%)$ & $3(4 \%)$ & 0 \\
\hline Pourabdollah [54], 2016 & $21 / 40(52.5 \%)$ & - & - & - \\
\hline Griff [30], 2014 & $41 / 52(79 \%)$ & 0 & 0 & 0 \\
\hline Hernández-Gonzáles [33], 2015 & $28 / 33(84 \%)$ & $4(12 \%)$ & 0 & 0 \\
\hline Hagmeyer [32], 2016 & $23 / 32(72 \%)$ & $6(19 \%)$ & $2(6 \%)$ & - \\
\hline Gershman [31], 2015 & - & $15(5 \%)$ & $16(5 \%)$ & - \\
\hline Ramaswamy [55], 2016 & $37 / 56(66 \%)$ & $11(20 \%)$ & $1(2 \%)$ & 0 \\
\hline Echevarria-Uraga [40], 2016 & $83 / 85(97 \%)$ & $3(3 \%)$ & $10(10 \%)$ & - \\
\hline Ravaglia [34], 2016 & $246 / 297(82.8 \%)$ & $60(20 \%)$ & 0 & $1(0.3 \%)$ \\
\hline Ussavarungsi [56], 2017 & $38 / 74(51 \%)$ & $1(1.4 \%)$ & $9(12 \%)$ & - \\
\hline DiBardino [19], 2017 & $14 / 25(56 \%)$ & $2(8 \%)$ & $3(12 \%)$ & - \\
\hline Bango-Alvarez [36], 2017 & $91 / 106(86 \%)$ & $5(4.7 \%)$ & 0 & 0 \\
\hline Kronborg-White [57], 2017 & $28 / 38(74 \%)$ & $10(26 \%)$ & $3(8 \%)$ & 0 \\
\hline Sriprasart [42], 2017 & $65 / 74(87.8 \%)$ & $5(7 \%)$ & $1(1 \%)$ & - \\
\hline Ravaglia [53], 2017 & - & $7(16 \%)$ & 0 & - \\
\hline Forceps biopsy & $25-65 \%$ & $0-14.3 \%$ & $0-6.0 \%$ & \\
\hline Wall [58], 1981 & $20 / 53(37.7 \%)$ & $2 / 52(3.8 \%)$ & 0 & 0 \\
\hline O’Brien [59], 1997 & $29 / 83(34.9 \%)$ & $10 / 83(14.3 \%)$ & $5 / 83(6.0 \%)$ & 0 \\
\hline Berbescu [13], 2006 & $7 / 22(31.8 \%)$ UIP & - & - & - \\
\hline Casoni [60], 2008 & $62 / 95(65 \%)$ & 0 & 0 & 0 \\
\hline Facciolongo [61], 2009 & - & $22 / 1,660(1.3 \%)$ & $21 / 1,660(1.3 \%)$ & 0 \\
\hline Tomassetti [12], 2012 & $13 / 64(25 \%)$ & $5 / 64(8 \%)$ & - & 0 \\
\hline Yarmus [23], 2013 & - & $1 / 21(4.76 \%)$ & 0 & 0 \\
\hline Pajares [28], 2014 & $11 / 38(29.1 \%)$ & $2 / 38(5.3 \%)$ & 0 & 0 \\
\hline Pourabdollah [54], 2016 & $14 / 26(53.8 \%)$ & - & - & - \\
\hline Gershman [31], 2015 & - & $9 / 286(3.15 \%)$ & $13 / 288(4.4 \%)$ & 0 \\
\hline Ramaswamy [55], 2016 & $16 / 56(29 \%)$ & - & - & - \\
\hline Sheth [62], 2017 & $13 / 33(39.4 \%)$ & - & - & - \\
\hline Surgical biopsy & $>69.9 \%$ & NA & No bleeding & Up to $9 \%$ \\
\hline Rena [63], 1999 & $50 / 58(86 \%)$ & NA & 0 & 0 \\
\hline Kreider [64], 2007 & $52 / 68(76.5 \%)$ & NA & 0 & $3 / 68(4.4 \%)$ \\
\hline Zhang [65], 2010 & $368 / 418(88.0 \%)$ & NA & 0 & $3 / 418(0.7 \%)$ \\
\hline Fibla [66], 2012 & $195 / 224(87 \%)$ & NA & 0 & - \\
\hline Blackhall [67], 2013 & $72 / 103(69.9 \%)$ & NA & 0 & $4 / 103(3.9 \%)$ \\
\hline Morris [68], 2014 & $49 / 66(74.2 \%)$ & NA & 0 & $1 / 66(1.5 \%)$ \\
\hline Rotolo [69], 2015 & $154 / 161(95.7 \%)$ & $\mathrm{NA}$ & 0 & $4 / 161(2.5 \%)$ \\
\hline Fibla [70], 2015 & $232 / 311(74.6 \%)$ & NA & 0 & $28(9 \%)$ \\
\hline Hutchinson [4], 2016 & - & $\mathrm{NA}$ & - & $2,051 / 32,022(6.4 \%)$ \\
\hline Hutchinson [71], 2016 & - & NA & - & $68 / 2820(2.4 \%)$ \\
\hline Ravaglia [34], 2016 & $140 / 150(98.7 \%)$ & NA & 0 & $4 / 150(2.7 \%)$ \\
\hline Sheth [62], 2017 & $232 / 311(75 \%)$ & NA & 0 & - \\
\hline Lieberman [72], 2017 & $47 / 47(100 \%)$ & NA & 0 & $1(2.1 \%)$ \\
\hline
\end{tabular}

AE, adverse event; UIP, usual interstitial pneumonia; NA, not applicable (after surgical lung biopsy usually a chest tube is applied). 
stains such as elastic Van Gieson as per pathologist preference). Two key aspects in handling and processing of TBCBs are:

1. Minimize tissue manipulation (through the entire process from removing the specimen from the probe to embedding in paraffin).

2. Embed and orientate the tissue in the paraffin block to maximize surface area on the slides.

Forcible separation of the tissue from the probe's tip may diminish the diagnostic yield. Therefore, attention to minimal tissue manipulation and maximized surface area on the slide greatly facilitates pattern recognition. Thawing in hand-warm water may facilitate to remove the specimen from the probe's tip. Some tissue should remain in the paraffin block after initial cuts (at least 40\%) to be available for furthers studies, special stains, etc. TBCB tissue is adequate for immunohistochemical and molecular studies that are done on other lung specimens.

Histological diagnosis of the UIP pattern is feasible on TBCB [48]. Elements of the UIP pattern (patchy fibrosis, fibroblastic foci, honeycomb changes) are identifiable with high confidence in cryosamples [47]. Additionally, in one study, the inter-observer variability between expert pathologists for diagnosing the UIP pattern on TBCB was similar to that described in SLB (0.72 vs. 0.86) [50]. Tests assessing the products of overexpression or underexpression of different molecular pathways (wnt, etc.) are feasible on cryobiopsy samples [51].

TBCBs have been shown to have a meaningful impact on diagnostic confidence in the MDD, which is comparable to that observed in SLB [50]. The NSIP or DIP patterns or other rarer and complicated lesions have also been identified in samples obtained by cryoprobes, although in a limited number of cases $[52,53]$. Thus, data on the clinical meaning of NSIP/DIP and other patterns on cryobiopsy have not been assessed yet. However, data on the prognostic impact of histological patterns documented by TBCB in patients with fibrosing ILD accumulated so far are promising.

Consistent with prior published guidelines, conventional forceps biopsies remain indicated in a minority of patients with DPLD, such as those having lesions along the lymphatic routes or in the centrilobular zones as assessed by CT (i.e., granulomatous diseases, carcinomatous lymphangitis, organizing pneumonia) [9, 54-72] (Table 1 ). The impact of TBCB in rapidly declining subjects is not yet well identified, and because of a risk of acute exacerbation, generally discouraged.

\section{Key Points}

a. TBCB samples should be processed very carefully after extraction.

b. The size of the histological samples influences the diagnostic yield. A sample size of $5 \mathrm{~mm}$ in diameter is suggested as sufficient.

\section{Contraindications and Safety Considerations}

Available data indicate pneumothorax to be a complication associated with TBCB. However, the rate varies considerably between different studies: from less than $1 \%$ to almost $30 \%[16,21-23,28,30-32,34,35,73,74]$. In a meta-analysis that included 15 studies comprising 994 patients, the average rate was $10 \%$ [34]; the same results were confirmed by a more recent meta-analysis of 13 studies with an incidence of postprocedural pneumothorax of 9.5\% (5.9-14.9\%) [35]. There are very few data regarding chest tube time, but when chest drainage was necessary, time of drainage was similar to that of drainage after VATS [34]. The risk of pneumothorax increases with UIP histology, fibrotic reticulation on HRCT scan, and with biopsies taken close to the pleura [27, 34].

Bleeding during cryobiopsy is common $[16,17,22,23$, $28,30,32,40,41,74-76]$, but is generally readily controlled endoscopically, e.g., by the use of bronchial blockers (Fogarty balloon or other tools) and/or use of rigid bronchoscopy [23, 27, 34, 40, 43, 76]. There is no generally accepted bleeding severity scale and therefore comparability of different papers is difficult. However, most papers grade on a scale of 4 steps: no bleeding, mild bleeding (e.g., requiring suction to clear but no other endoscopic procedures), moderate bleeding (e.g., requiring endoscopic procedures like bronchial occlusion-collapse and/or instillation of ice-cold saline), and severe bleeding (e.g., causing hemodynamic or respiratory instability, requiring tamponade or other surgical interventions, transfusions or admission to the intensive care unit) [77]. In a previous meta-analysis, moderate bleeding after cryobiopsy was observed in 65 cases among 383 patients from 12 studies (16.9\%), with an overall pooled probability of developing a moderate bleeding of about 0.12 (CI 0.020.25) [34]. No episodes of severe bleeding, as defined above, are reported in literature (in some papers bleeding has been reported as severe but was controlled by placement of bronchial blocker or catheter) [41] and no bleeding-related deaths have been reported after cryobiopsy, but the authors are aware of unpublished cases in which severe bleeding led to death when a bronchial blocker was 
not preventively employed. A recently published report highlights the risk of potentially life-threatening complications when these precautions are not taken [19]. Abnormal coagulation parameters and use of clopidogrel or other new antiplatelet drugs are considered contraindications; treatment with aspirin is regarded as a relative contraindication. In the absence of more definitive data and given the increased bleeding risk compared to conventional forceps biopsies, a conservative approach would be to hold all medications potentially associated with increased bleeding risk. Thrombocytopenia $\left(<50 \times 10^{9} / \mathrm{L}\right)$ is suggested to be a contraindication for biopsies during flexible bronchoscopy [76]. These values may be accepted also for TBCB until data on this topic will become available.

Patients with clinical or radiological signs of pulmonary hypertension should have a preprocedural evaluation of pulmonary artery pressure by echocardiography or right heart catheterization. An estimated systolic pulmonary artery pressure $>50 \mathrm{~mm} \mathrm{Hg}$ on echocardiography indicates an increased likelihood of pulmonary hypertension $[78,79]$ and, in the absence of more definitive data, is considered a relative contraindication to TBCB [76].

Mortality due to acute exacerbation of UIP after TBCB has been reported in 2 cases as described before [27, 41]. Acute deterioration in respiratory status should be considered a relative contraindication, although the decision needs to be individualized based on assessment of benefits and risks. Studies documenting complications, diagnostic yield, and clinical role of TBCB in this specific clinical scenario are needed considering that BAL could have some diagnostic impact in diffuse lung disorders with a rapid deterioration [80], although with potential risks and low yield in some cases [81].

Anecdotal data suggest that complications are more frequent when pulmonary function is severely impaired. We suggest that diffusing capacity $<35 \%$ or forced vital capacity (FVC) $<50 \%$ should be considered as a relative contraindication to TBCB on safety grounds. This limitation is drawn from data reported in studies dealing with SLB. Additionally, in the subset of patients with severe fibrosing ILD, the risk-benefit analysis is less advantageous, because in these patients it seems that the prognostic significance of an exact histological diagnosis is reduced [46] and data on the efficacy of a specific "antifibrotic" drug on patients with severe IPF are still scanty [6, $7,46,82-84]$. A high body mass index $($ BMI >35) can result in failure of the procedure [27], mainly because of desaturation in intubated and spontaneously breathing patients.
Exclusion criteria for TBCBs vary substantially across studies. Forced expiratory volume in the first second $\left(\mathrm{FEV}_{1}\right)<0.8 \mathrm{~L}$ or $<50 \%$ predicted, $\mathrm{FVC}<50 \%$ predicted, and diffusing capacity of the lungs for carbon monoxide (DLCO) $<35$ or $<50 \%$ predicted have been used to exclude biopsy candidates in some series, though not in all [16, 27, 34]. Transthoracic echocardiography has been used in some series to exclude those with estimated pulmonary arterial systolic pressure $>40 \mathrm{~mm} \mathrm{Hg}$, though routine preprocedural transthoracic echocardiography is not universally obtained [16, 22, 27, 34]. Significant hypoxemia, defined as $\mathrm{PaO}_{2}<55-60 \mathrm{~mm} \mathrm{Hg}$ on room air or while receiving $2 \mathrm{~L} / \mathrm{min}$ of nasal oxygen has also been considered a contraindication by some but not others [22, 27, 28]. Additionally, a study evaluated TBCB in mechanically ventilated patients in the intensive care unit, though the experience remains anecdotal at this time [85].

The authors are aware that TBCB has been performed safely in a wide age range of patients. Therefore, it was the consensus of the group that no age limit should be suggested at this time, as long as comorbidities and fitness for anesthesia are considered and felt to be suitable for the procedure.

\section{Key Points}

a. The major risks after TBCB are pneumothorax and bleeding.

b. Bleeding diathesis and anticoagulant therapy, treatment with thienopyridines or other new antiplatelet drugs and thrombocytopenia with platelets $<50 \times 10^{9} / \mathrm{L}$ should be considered as contraindications.

c. Pulmonary hypertension may increase the bleeding risk and is therefore considered as a relative contraindication.

d. No age limits are suggested.

e. FVC $<50 \%$ and DLCO $<35 \%$ of the predicted values are regarded as relative contraindications.

\section{How Should TBCB Be Performed and in What Procedural Environment?}

The methods used to perform TBCB vary substantially across different centers and among bronchoscopists (Table 2). For example, a large series reported obtaining TBCB specimens in sedated patients without intubation or prophylactic bronchial blocker placement to control bleeding [31]. Studies reporting the use of laryngeal mask airway have been published [86-88]. However, in the majority of centers, TBCB are usually performed in intubat- 
Table 2. Transbronchial cryobiopsy for diffuse lung disease: different approaches

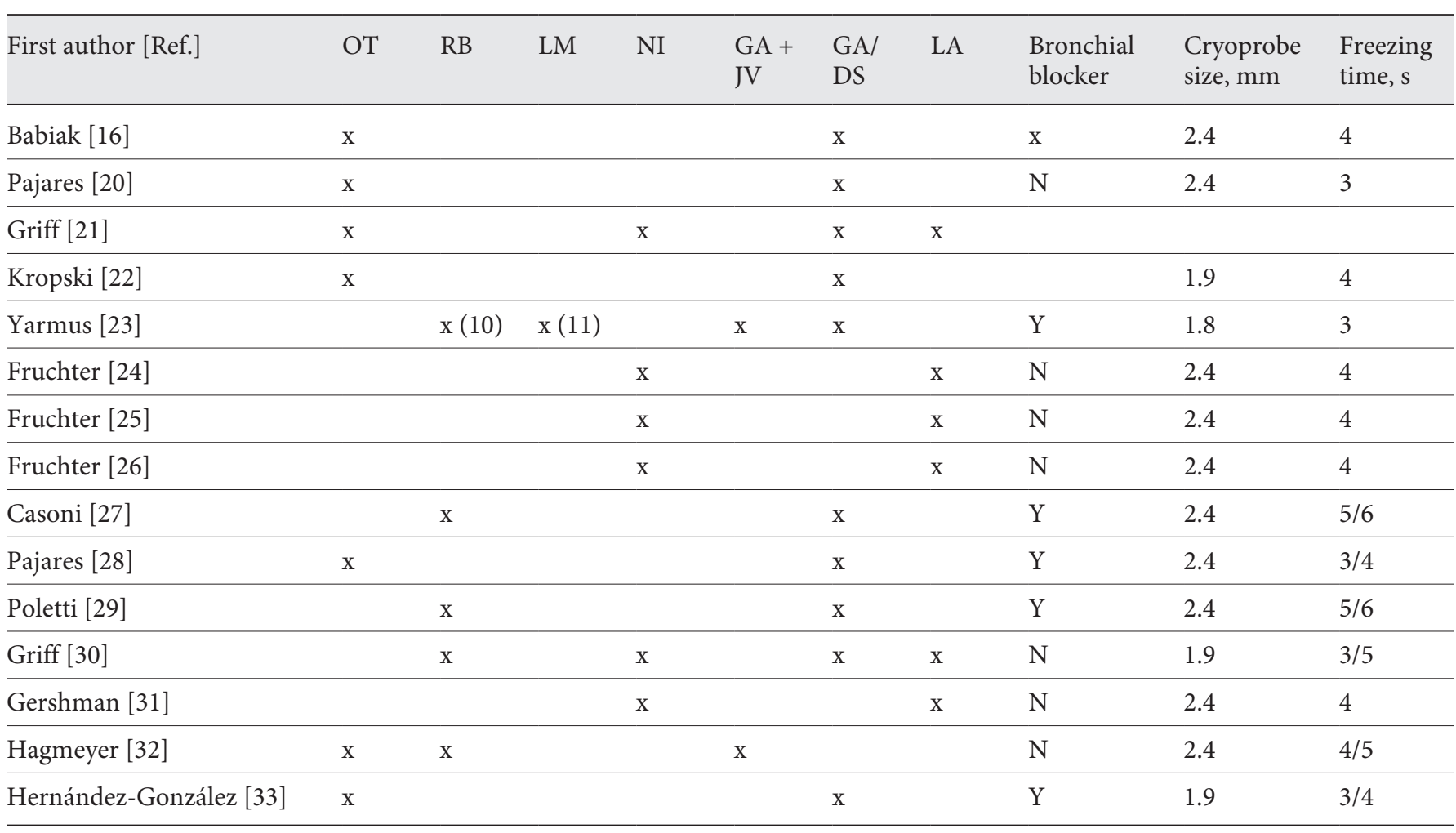

Modified from [17]. OT, orotracheal tube; RB, rigid bronchoscope; LM, laryngeal mask; NI, no intubation; GA, general anesthesia; JV, jet ventilation; DS, deep sedation; LA, local anesthesia; Y, yes; N, no; $x$, method used.

ed patients with prophylactic placement of a bronchial blocker, either with conventional endotracheal tube or through a rigid bronchoscope $[17,75]$.

\section{Is TBCB without Sedation Possible?}

Coughing or patient movement may result in displacement of the cryoprobe during $\mathrm{TBCB}$, which may result in biopsies either too proximal (increased risk of bleeding) or too distal (increased risk of pneumothorax). Therefore, general anesthesia or deep sedation is advised. However, spontaneous breathing does not seem to interfere with the procedure [17,34], and therefore neuromuscular blockade does not appear necessary. In the experience of the group, jet ventilation during TBCB is possible.

\section{Where Should the Cryoprobe Be Placed?}

Biopsies should be taken in the distal part of the lung parenchyma, usually in the most affected areas, avoiding the most densely fibrotic lung parenchyma that is of limited diagnostic value. Distances of less than $1 \mathrm{~cm}$ to the pleura are associated with a significantly increased risk of pneumothorax [27]. Conversely, biopsies obtained too proximally from the middle third of the lung increase the risk of severe bleeding due to the fact that in this region, medium-sized arterial vessels that accompany the bronchi lack the protective shield afforded by complete cartilage plates present in more central airways [47]. Additionally, biopsies obtained closer to the secondary lobule, more distally, are felt to provide histology specimens more appropriate for the diagnosis of UIP (Fig. 1). Therefore, we recommend that biopsies be obtained under fluoroscopic guidance by advancing the cryoprobe until gentle contact with the visceral pleura is achieved (if placement in the subpleural area is not possible, no biopsy should be taken and another lung area should be chosen) after which the probe should be retracted by $1 \mathrm{~cm}$, which represents approximately the length of the metallic tip of the current available cryoprobes (ERBE CA and ERBE CA II, Germany), and biopsies be obtained [17, 27]. This suggestion is based on data reported in studies dealing with diagnostic yield and complications: pneumothorax seems to be more frequent when biopsies are 
Fig. 1. Biopsies should be taken in the distal part of the lung parenchyma. Distances of less than $1 \mathrm{~cm}$ to the pleura are associated with a significantly increased risk of pneumothorax. Conversely, biopsies obtained too proximally from the middle third of the lung increase the risk of severe bleeding; additionally, biopsies obtained closer to the secondary lobule, more distally, are felt to provide histology specimens more appropriate for the diagnosis of UIP.

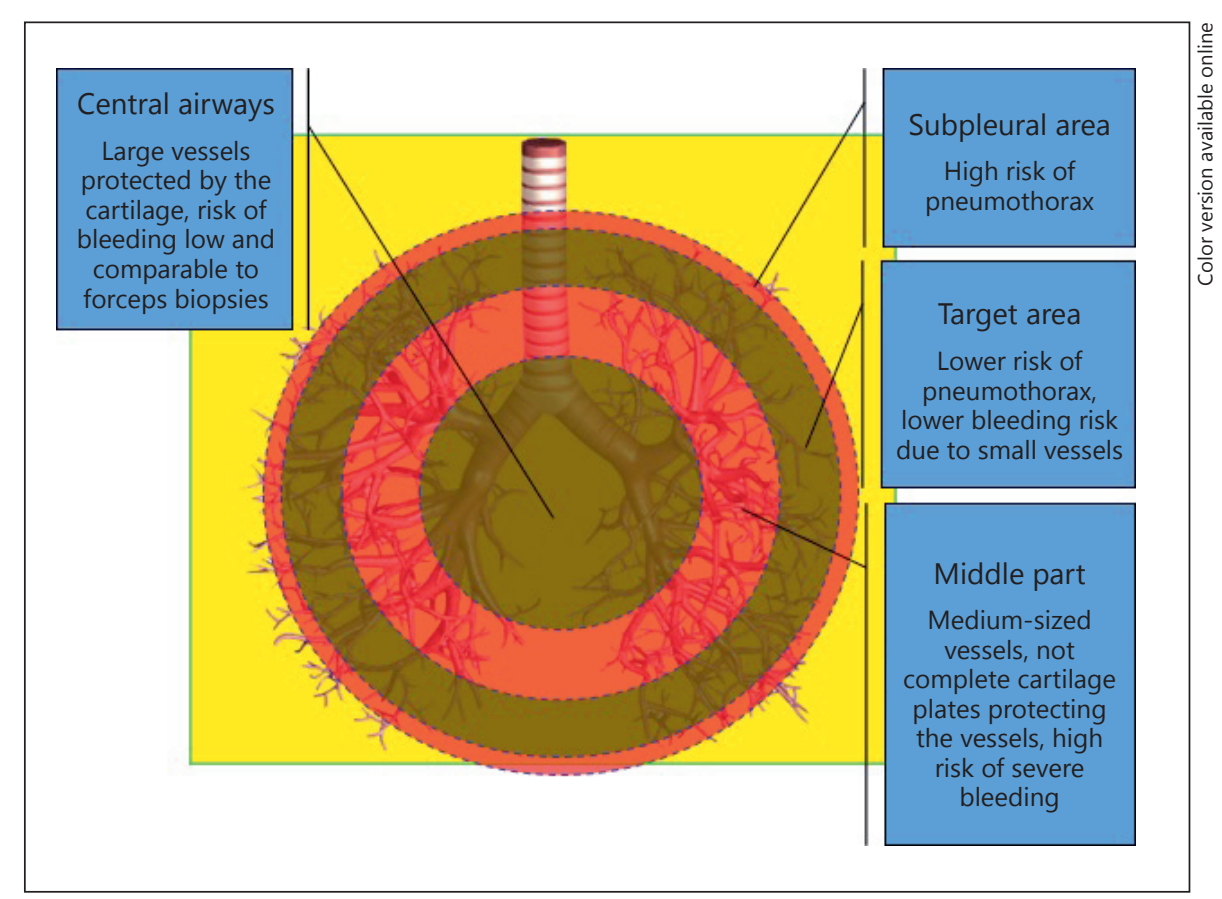

taken close to the pleura; however, sampling of the subpleural region allows to identify the UIP pattern with higher confidence [27, 47].

\section{Which Cryoprobe Should Be Used and How Long Should the Freezing Time Be?}

Both the 2.4- and 1.9-mm outer diameter cryoprobes have been used for TBCB [16, 22, 25, 27]. While the 1.9$\mathrm{mm}$ cryoprobe can be used with a regular adult bronchoscope with a 2-mm working channel, we recommend using a therapeutic bronchoscope with a larger working channel in general. In case of bleeding, a larger working channel helps control the bleeding. In addition, the lesser friction allowed by a larger working channel facilitates identification of the time of contact with the pleura when the cryoprobe is advanced to the periphery. In order to achieve the same specimen size, however, a longer freezing time may be necessary when using the $1.9-\mathrm{mm}$ probe in comparison to the $2.4-\mathrm{mm}$ probe $[17,89]$. The freezing capacity is further influenced by the cryosurgical system (ERBE CA vs. ERBE CA II), the cooling gas which is used, and possibly, the characteristics of the lung tissue being biopsied. Accordingly, it is advised to test the freezing capacity of the selected cryoprobe in a water bath before the cryobiopsy is performed. This allows estimation of the required freezing time needed to harvest an adequate specimen. When using carbon dioxide, a freezing time of
$5 \mathrm{~s}$ with the $2.4-\mathrm{mm}$ probe and $7 \mathrm{~s}$ with the $1.9-\mathrm{mm}$ probe should be sufficient in the majority of cases. The use of nitrous oxide as cooling gas reduces the necessary freezing time in comparison to carbon dioxide, but is not typically used in endoscopy suites due to regulatory issues. Appropriate placement of the $2.4-\mathrm{mm}$ cryoprobe is more difficult than with the $1.9-\mathrm{mm}$ cryoprobe, because the likelihood of being obstructed by a carina on the way out to the lung periphery is higher with the larger cryoprobe than with the smaller cryoprobe. Several pilot studies have described the use of a smaller 1.1-mm cryoprobe, which can be pulled through a sheath placed in the working channel of the bronchoscope, allowing the bronchoscope to stay in place during cryoprobe retrieval and decreasing the concerns for uncontrolled endobronchial bleeding $[90,91]$. However, it is unclear whether these smaller cryobiopsies will result in diagnostic yields similar to those described with larger probes [92].

\section{How Many Cryobiopsies Should Be Obtained?}

The number of biopsy needed for diagnosis is influenced by the size of the specimen, the degree of heterogeneity of the disease, and the distribution of the parenchymal pathology. Therefore, the optimal number of biopsies cannot be uniformly established, although in the majority of centers 3-5 biopsies are usually taken. However, a recent study suggested that biopsies from different 
segments within the same lobe are associated with a higher diagnostic yield compared to biopsies in the same segment [53]. Multiple biopsies are usually undertaken in an effort to reduce sampling error, but data on the different strategies adopted to sample lung tissue are still missing in the literature; no prospective studies have been published yet in terms of diagnostic yield and rates of complications. While it remains unclear whether TBCB should be obtained from 2 different lobes, prior data on interlobar heterogeneity of UIP support this practice, mainly when the CT scan does not show a clear gradient profusion of the pattern or when different patterns are present in different lobes, if optimal placement of the cryoprobe and bronchial blocker can be achieved [53].

\section{How to Optimize Safety, Especially Bleeding Risks}

As both the flexible bronchoscope and the cryoprobe need to be removed en bloc (since the biopsy size does not allow its retrieval through the working channel of the bronchoscope), there is significant blind time during which no control of the endobronchial system is possible. In case of severe bleeding, access to the airways may be difficult or almost impossible without intubation when the bronchoscope has been removed out of the airway after the biopsy. Therefore, intubation either with the rigid bronchoscope or a flexible endotracheal tube is highly recommended [93]. Prophylactic placement of a Fogarty balloon or a bronchial blocker in the bronchus leading to the biopsied area and its inflation immediately after TBCB prevents blood from entering the central airways in case of significant bleeding and thus minimizes the risks associated with this blind period. Placement of a Fogarty balloon or a bronchial blocker is recommended, especially in the case of intubation with a flexible tube, when immediate tamponade is not possible. It is important to obtain history of allergy to latex prior to the procedure when latex products are used. If using a rigid bronchoscope without prophylactic balloon placement, a long instrument (bronchoscope) should be used. The rigid bronchoscope should be advanced at least in the main stem bronchus but preferably in the lobar bronchus where the TBCB will be obtained. In case of severe bleeding, there is no risk to lose the orientation and the bleeding can be controlled by tamponade.

A postprocedural chest X-ray or ultrasound examination should be performed to assess for the occurrence of pneumothorax either immediately (if desaturation, persistent cough and/or thoracic pain are present) or $2 \mathrm{~h}$ after the end of the procedure if the patient is asymptomatic [94]. This is particularly relevant if the patient is in the outpatient setting. Patients should be observed in the recovery area as per local institutional guidelines.

\section{Key Points}

a. We suggest that TBCBs be performed in intubated patients under deep sedation or general anesthesia.

b. We suggest that if a flexible endotracheal tube is used for airway management, an endobronchial blocker or a Fogarty balloon be used prophylactically in order to control bleeding and prevent central airway blood flooding. In case of intubation with a rigid bronchoscope, prophylactic balloon placement may be helpful, but is not felt to be mandatory.

c. We suggest that $3-5$ biopsies be obtained $1 \mathrm{~cm}$ from the visceral pleura.

d. We suggest that fluoroscopic guidance be used.

\section{Who Should Perform TBCBs?}

The available data on TBCB have largely been reported by expert interventional pulmonology groups, familiar with advanced diagnostic and therapeutic bronchoscopic procedures. These procedures also include management of massive hemoptysis and tension pneumothorax after or during transbronchial biopsies. Most TBCBs for DPLD reported in the literature to date have been performed in the operating room or in a bronchoscopy suite with advanced airway equipment and rapid anesthesia support available. While some procedures have been performed on an outpatient basis, inpatient emergency management was immediately available if escalation of care was needed. It is unclear, at this time, whether less experienced bronchoscopists will be able to perform this procedure safely. Additionally, the majority of the reported data are retrospective in nature, and subject to biases inherent in these study designs. Taking these facts into account, it is recommended that TBCB be performed by interventional pulmonologists appropriately trained in a center with TBCB experience and familiar with advanced therapeutic bronchoscopic procedures (management of massive hemoptysis and tension pneumothorax) with readily access to interventional radiology and thoracic surgery.

TBCB training using simulation models may be technically possible, but data are lacking and in general, optimal training for TBCB remains to be defined. The authors recognize the need for the establishment of competency and quality standards for the procedure and the need for further research. Ultimately, it is the authors' beliefs that these questions will be better addressed by well-designed 
comparative research studies and the establishment of a multicenter registry, to ensure that clinical outcomes of patients undergoing TBCB for DPLD be captured and analyzed effectively and accurately.

\section{Key Points}

a. We suggest that TBCBs be performed by interventional bronchoscopists trained at a center with experience in TBCBs in the management of potential complications like bleeding, pneumothorax, or respiratory failure.

b. We suggest that TBCBs be performed in the operating room with full anesthesia support or in a dedicated bronchoscopy suite with emergency equipment immediately available with possibility to admit the patient to the intensive care unit and escalate care if needed.

c. We suggest that a prospective registry be developed and all TBCBs recorded to better capture morbidity and mortality data.

\section{Closing Remarks}

TBCB is a promising technique, which substantially expands the pulmonary armamentarium in the diagnosis of DPLDs. The adoption of ancillary techniques such as navigation systems or genomic tools could increase its role in the diagnostic workup. Further studies and a data registry addressing diagnostic yield, safety, and technical aspects are needed; a multicenter randomized controlled trial study could be particularly needed, looking at patients - important endpoints (disease progression, death) - and comparing TBCBs to standard of care. This will also open opportunities for synergizing collaborative research and training activities. Based on the known risk of transbronchial biopsies in general and TBCBs in particular, it seems prudent to follow the standardized approaches suggested in this document to maximize the diagnostic yield and accuracy and increase patient safety.

\section{References}

1 Maldonado F, Aksamit TR: Interstitial lung diseases; in: Mayo Clinic Internal Medicine Board Review, ed 10. Mayo Clinic Scientific Press, 2013.

2 Mathai SK, Newton CA, Schwartz DA, Garcia CK: Pulmonary fibrosis in the era of stratified medicine. Thorax 2016;71:1154-1160.

3 Tomassetti S, Piciucchi S, Tantalocco P, Dubini A, Poletti V: The multidisciplinary approach in the diagnosis of idiopathic pulmonary fibrosis: a patient case-based review. Eur Respir Rev 2015;24:69-773.

4 Hutchinson JP, Fogarty AW, McKeever TM, Hubbard RB: In-Hospital Mortality after surgical lung biopsy for interstitial lung disease in the United States. 2000-2011. Am J Respir Crit Care Med 2016;193:1161-1167.

5 Utz JP, Ryu JH, Douglas WW, Hartman TE, Tazelaar HD, et al: High short-term mortality following lung biopsy for usual interstitial pneumonia. Eur Respir J 2001;17:175-179.

6 King TE Jr, Bradford WZ, Castro-Bernardini $S$, et al: A phase 3 trial of pirfenidone in patients with idiopathic pulmonary fibrosis. $\mathrm{N}$ Engl J Med 2014;370:2083-2092.

7 Richeldi L, du Bois RM, Raghu G, et al: Efficacy and safety of nintedanib in idiopathic pulmonary fibrosis. N Engl J Med 2014;370: 2071-2082.

8 Raghu G, Collard HR, Egan JJ, Martinez FJ, Behr J, Brown KK, Colby TV, Cordier JF, Flaherty KR, Lasky JA, et al: An official ATS/ ERS/JRS/ALAT statement: idiopathic pulmonary fibrosis: evidence-based guidelines for diagnosis and management. Am J Respir Crit Care Med 2011;183:788-824.
9 Poletti V, Chilosi M, Olivieri D: Diagnostic invasive procedures in diffuse infiltrative lung diseases. Respiration 2004;71:107-119.

10 Colby TV: The pathologist's approach to bronchoscopic biopsies. Pathologica 2010; 102:432-442.

11 Benzaquen S, Aragaki-Nakahodo AA: Bronchoscopic modalities to diagnose sarcoidosis. Current Opin Pulm Med 2017;23:433-438.

12 Tomassetti S, Cavazza A, Colby TV, Ryu JH, Nanni O, Scarpi E, Tantalocco P, Buccioli M, Dubini A, Piciucchi S, Ravaglia C, Gurioli C, Casoni GL, Gurioli C, Romagnoli M, Poletti $\mathrm{V}$ : Transbronchial biopsy is useful in predicting UIP pattern. Respir Res 2012;13:96.

13 Berbescu EA, Katzenstein AL, Snow JL, Zisman DA: Transbronchial biopsy in usual interstitial pneumonia. Chest 2006;129:11261131.

14 Shim HS, Park MS, Park IK: Histopathologic findings of transbronchial biopsy in usual interstitial pneumonia. Pathol Int 2010;60:373377.

15 Poletti V, Ravaglia C, Gurioli C, Piciucchi S, Dubini A, Cavazza A, Chilosi M, Rossi A, Tomassetti S: Invasive diagnostic techniques in idiopathic interstitial pneumonias. Respirology 2016;21:44-50.

16 Babiak A, Hetzel J, Krishna G, Fritz P, Moeller P, Balli T, Hetzel M: Tranbronchial cryobiopsy: a new tool for lung biopsies. Respiration 2009;78:203-208.

17 Poletti V, Hetzel J: Transbronchial cryobiopsy in diffuse parenchymal lung disease: need for procedural standardization. Respiration 2015;90:275-278.
18 Lentz RJ, Maldonado F: Acute exacerbations of interstitial lung disease: don't just do something, stand there! Respirology 2017;22:215216.

19 DiBardino DM, Haas AR, Lanfranco AR, Litzky LA, Sterman D, Bessich JL: High complication rate after introduction of transbronchial cryobiopsy into clinical practice at an Academic Medical Center. Ann Thorac Soc 2017;14:851-857.

20 Pajares V, Torrego A, Puzo C, Lerma E, Gil De Bernabé MA, Franquet T: Transbronchial lung biopsy using cryoprobes (in Spanish). Arch Bronconeumol 2010;46:111-115.

21 Griff S, Ammenwerth W, Schönfeld N, Bauer TT, Mairinger T, Blum TG, Kollmeier J, Grüning W: Morphometrical analysis of transbronchial cryobiopsies. Diagn Pathol 2011;6:53.

22 Kropski JA, Pritchett JM, Mason WR, Sivarajan L, Gleaves LA, Johnson JE, Lancaster LH, Lawson WE, Blackwell TS, Steele MP, Loyd JE, Rickman OB: Bronchoscopic cryobiopsy for the diagnosis of diffuse parenchymal lung disease. PLoS One 2013;12:e78674.

23 Yarmus L, Akulian J, Gilbert C, Illei P, Shah P, Merlo C, Orens J, Feller-Kopman D: Cryoprobe transbronchial lung biopsy in patients after lung transplantation: a pilot safety study. Chest 2013;143:621-626.

24 Fruchter O, Fridel L, Rosengarten D, et al: Transbronchial cryo-biopsy in lung transplantation patients: first report. Respirology 2013;18:669-673. 
25 Fruchter O, Fridel L, Rosengarten D, et al: Transbronchial cryobiopsy in immunocompromised patients with pulmonary infiltrates: a pilot study. Lung 2013;191:619-624.

26 Fruchter O, Fridel L, El Raouf BA, AbdelRahman N, Rosengarten D, Kramer MR: Histological diagnosis of interstitial lung diseases by cryo-transbronchial biopsy. Respirology 2014; 19:683-688.

27 Casoni GL, Tomassetti S, Cavazza A, et al: Transbronchial lung cryobiopsy in the diagnosis of fibrotic interstitial lung diseases. PLoS One 2014;9:e86716.

28 Pajares V, Puzo C, Castillo D, Lerma E, Montero MA, Ramos-Barbón D, Amor-Carro O, Gil de Bernabé A, Franquet T, Plaza V, Hetzel J, Sanchis J, Torrego A: Diagnostic yield of transbronchial cryobiopsy in interstitial lung disease: a randomized trial. Respirology 2014; 19:900-906.

29 Poletti V, Casoni GL, Gurioli C, Ryu JH, Tomassetti S: Lung cryobiopsies: a paradigm shift in diagnostic bronchoscopy? Respirology 2014; 19:645-654.

30 Griff S, Schönfeld N, Ammenwerth W, Blum TG, Grah C, Bauer TT, Grüning W, Mairinger T, Wurps H: Diagnostic yield of transbronchial cryobiopsy in non-neoplastic lung disease: a retrospective case series. BMC Pulm Med 2014;14:171.

31 Gershman E, Fruchter O, Benjamin F, Nader AR, Rosengarten D, Rusanov V, Fridel L, Kramer MR: Safety of cryo-transbronchial biopsy in diffuse lung diseases: analysis of three hundred cases. Respiration 2015;90:40-46.

32 Hagmeyer L, Theegarten D, Wohlschläger J, Treml M, Matthes S, Priegnitz C, Randerath WJ: The role of transbronchial cryobiopsy and surgical lung biopsy in the diagnostic algorithm of interstitial lung disease. Clin Respir J 2016;10:589-595.

33 Hernández-González F, Lucena CM, Ramírez J, Sánchez M, Jimenez MJ, Xaubet A, Sellares J, Agustí C: Cryobiopsy in the diagnosis of diffuse interstitial lung disease: yield and costeffectiveness analysis. Arch Bronconeumol 2015;51:261-267.

34 Ravaglia C, Bonifazi M, Wells AU, Tomassetti S, Gurioli C, et al: Safety and diagnostic yield of transbronchial lung cryobiopsy in diffuse parenchymal lung diseases: a comparative study versus video-assisted thoracoscopic lung biopsy and a systematic review of the literature. Respiration 2016;91:215-227.

35 Iftikhar IH, Alghothani L, Sardi A, Berkowitz D Musani AI: Transbronchial lung cryobiopsy and video-assisted thoracoscopic lung biopsy in the diagnosis of diffuse parenchymal lung disease: a meta-analysis of diagnostic test accuracy. Ann Am Thorac Soc 2017; 14:11971211.

36 Bango-Alvarez A, Ariza-Prota M, Torres-Rivas $\mathrm{H}$, et al: Transbronchial cryobiopsy in interstitial lung disease: experience in 106 cases - how to do it. ERJ Open Res 2017;3: 00148-2016.
37 Stroup DF, Berlin JA, Morton SC, Olkin I, Williamson GD, Rennie D, Moher D, Becker BJ, Sipe TA, Thacker SB: Meta-analysis of observational studies in epidemiology: a proposal for reporting. Meta-analysis Of Observational Studies in Epidemiology (MOOSE) group. JAMA 2000;283:2008-2012.

38 Spagnolo P, Tzouvelekis A, Maher TM: Personalized medicine in idiopathic pulmonary fibrosis: facts and promises. Curr Opin Pulm Med 2015;21:470-478.

39 Sánchez-Cabral O, Martínez-Mendoza D, Fernandez-Bussy S, Perea-Talamantes C, Martínez-Orozco JA, Patricio SantillánDoherty P, Reyes-Terán G: Utility of transbronchial lung cryobiopsy in non-interstitial diseases. Respiration 2017;94:285-292.

40 Echevarria-Uraga JJ, Pèerez-Izquierdo J, Garcìa-Garai $\mathrm{N}$, Gòmez-Jiménez $\mathrm{E}$, AramburuOjembarrena A, Tena-Tudanca L, MiguélezVidales JL, Capelastequi-Saiz A: Usefulness of an angioplasty balloon as selective bronchial blockade device after transbronchial cryobiopsy. Respirology 2016:21:1094-1099.

41 Hagmeyer L, Theegarten D, Treml M, Priegnitz C, Randerath W: Validation of transbronchial cryobiopsy in interstitial lung disease - interim analysis of a prospective trial and critical review of the literature. Sarcoidosis Vasc Diffuse Lung Dis 2016;33:2-9.

42 Sriprasart T, Aragaki A, Baughman R, Wikenheiser-Brokamp K, Khanna G, Tanase D, Kirschner M, Benzaquen S: A Single US center experience of transbronchial lung cryobiopsy for diagnosing interstitial lung disease with a 2 -scope technique. J Bronchology Interv Pulmonol 2017;24:131-135.

43 Tomic R, Cortes-Puentes GA, Murugan P, Joo Kim H, Amin K, Dinkier HE: Acute exacerbation of interstitial lung disease after cryobiopsy. J Bronchology Interv Pulmonol 2017; 24:319-322.

44 Qiu M, Chen Y, Ye Q: Risk factors for acute exacerbation of idiopathic pulmonary fibrosis: a systematic review and meta-analysis. Clin Respir J 2017, Epub ahead of print.

45 Fujimoto K, Taniguchi H, Johkoh $\mathrm{T}$, et al: Acute exacerbation of idiopathic pulmonary fibrosis: high resolution CT scores predict mortality. Eur Radiol 2012;22:83-92.

46 Latsi PI, du Bois RM, Nicholson AG, et al: Fibrotic idiopathic interstitial pneumonia: the prognostic value of longitudinal functional trends. Am J Respir Crit Care Med 2003;168: 531-537.

47 Colby TV, Tomassetti S, Cavazza A, Dubini A, Poletti V: Transbronchial cryobiopsy in diffuse lung disease: update for the pathologist. Arch Pathol Lab Med 2017;141:891-900.

48 Poletti V, Gurioli C, Piciucchi S, Rossi A, Ravaglia $C$, Dubini A, Asioli S, Casoni GL: Intravascular large $B$ cell lymphoma presenting in the lung: the diagnostic value of transbronchial cryobiopsy. Sarcoidosis Vasc Diffuse Lung Dis 2015;31:354-358.
49 Piciucchi S, Dubini A, Tomassetti S, Sanna S, Ravaglia C, Carloni A, Gurioli C, Gurioli C, Colby TV, Poletti V: Angiosarcoma in the chest: radiologic-pathologic correlation: case report. Medicine (Baltimore) 2016;95:e5348.

50 Tomassetti S, Wells AU, Costabel U, Cavazza A, Colby TV, et al: Bronchoscopic lung cryobiopsy increases diagnostic confidence in the multidisciplinary diagnosis of idiopathic pulmonary fibrosis. Am J Respir Crit Care Med 2016;193:745-752.

51 Poletti V, Ravaglia C, Tomassetti S: Transbronchial cryobiopsy in diffuse parenchymal lung diseases. Curr Opin Pulm Med 2016;22: 289-296.

52 Dias C, Mota P, Neves I, Guimaraes S, Souto Moura C, Morais A: Transbronchial cryobiopsy in the diagnosis of desquamative interstitial pneumonia. Rev Port Pneumol 2006; 22:288-290.

53 Ravaglia C, Wells AU, Tomassetti S, Dubini A, Cavazza A, et al: Transbronchial lung cryobiopsy in diffuse parenchymal lung disease: comparison between biopsy from 1 segment and biopsy from 2 segments - diagnostic yield and complications. Respiration 2017;93:285292.

54 Pourabdollah M, Shamaei M, Karimi S, Karimi M, Kiani A, Jabbari HR: Transbronchial lung biopsy: the pathologist's point of view. Clin Respir J 2016;10:211-216.

55 Ramaswamy A, Homer R, Killam J, Pisani MA, Murphy TE, Araujo K, Puchalski J: Comparison of transbronchial and cryobiopsies in evaluation of diffuse parenchymal lung disease. J Bronchology Interv Pulmonol 2016; 23:14-21.

56 Ussavarungsi K, Kern RM, Roden AC, Ryu JH, Edell ES: Transbronchial cryobiopsy in diffuse parenchymal lung disease: retrospective analysis of 74 cases. Chest 2017;151:400408

57 Kronborg-White S, Folkersen B, Rasmussen TR, Voldby N, Madsen LB, Rasmussen F, Poletti V, Bendstrup E: Introduction of cryobiopsies in the diagnostics of interstitial lung diseases - experiences in a referral center. Eur Clin Respir J 2017;4:1274099.

58 Wall CP, Gaensler EA, Carrington CB, Hayes JA: Comparison of transbronchial and open biopsies in chronic infiltrative lung diseases. Am Rev Respir Dis 1981;123:280-285.

59 O'Brien JD, Ettinger NA, Shevlin D, Kollef $\mathrm{MH}$ : Safety and yield of transbronchial biopsy in mechanically ventilated patients. Crit Care Med 1997;25:440-446.

60 Casoni GL, Gurioli C, Chhajed PN, Chilosi M, Zompatori M, Olivieri D, Poletti V: The value of transbronchial lung biopsy using jumbo forceps via rigid bronchoscope in diffuse lung disease. Monaldi Arch Chest Dis 2008;69:59-64.

61 Facciolongo N, Patelli M, Gasparini S, Lazzari Agli L, Salio M, Simonassi C, Del Prato B, Zanoni P: Incidence of complications in bronchoscopy. Multicentre prospective study of 20,986 bronchoscopies. Monaldi Arch Chest Dis 2009;71:8-14. 
62 Sheth JS, Belperio JA, Fishbein MC, Kazerooni EA, Lagstein A, Murray S, Myers JL, Simon RH, Sisson TH, Sundaram B, White ES, Xia M, Zisman D, Flaherty KR: Utility of transbronchial versus surgical lung biopsy in the diagnosis of suspected fibrotic interstitial lung disease. Chest 2017;151:389-399.

63 Rena O, Casadio C, Leo F, Giobbe R, Cianci R, Baldi S, Rapellino M, Maggi G: Videothoracoscopic lung biopsy in the diagnosis of interstitial lung disaese. Eur J Cardiothorac Surg 1999;16:624-627.

64 Kreider ME, Hansen-Flaschen J, Ahmad NN, Rossman MD, Kaiser LR, Kucharczuk JC, Shrager JN: Complications of video-assisted thoracoscopic lung biopsy in patients with interstitial lung disease. Ann Thorac Surg 2007; 83:1140-1144.

65 Zhang D, Liu Y: Surgical lung biopsies in 418 patients with suspected interstitial lung disease in China. Intern Med 2010;49:10971102.

66 Fibla JJ, Molins L, Blanco A, Royo I, Martínez Vallina P, Martínez N, García Barajas S, Gomez A, Estors M, Moldes M, Fernández E, Xaubet A: Video-assisted thoracoscopic lung biopsy in the diagnosis of interstitial lung disease: a prospective, multi-center study in 224 patients. Arch Bronconeumol 2012;48:8185.

67 Blackhall V, Asif M, Renieri A, Civitelli S, Kirk A, Jilaihawi A, Granato F: The role of surgical lung biopsy in the management of interstitial lung disease: experience from a single institution in the UK. Interact Cardiovasc Thorac Surg 2013;17:253-257.

68 Morris D, Zamvar V: The efficacy of videoassisted thoracoscopic surgery lung biopsies in patients with interstitial lung disease: a retrospective study of 66 patients. J Cardiothorac Surg 2014;9:45.

69 Rotolo N, Imperatori A, Dominioni L, Facchini A, Conti V, Castiglioni M, Spanevello A: Efficacy and safety of surgical lung biopsy for interstitial disease. Experience of 161 consecutive patients from a single institution in Italy. Sarcoidosis Vasc Diffuse Lung Dis 2015;32: 251-258.

70 Fibla JJ, Brunelli A, Allen MS, Wigle D, Shen R, Nichols F, Deschamps C, Cassivi SD: Do the number and volume of surgical lung biopsies influence the diagnostic yield in interstitial lung disease? A propensity score analysis. Arch Bronconeumol 2015;51:76-79.

71 Hutchinson JP, McKeever TM, Fogarty AW, Navaratnam V, Hubbard RB: Surgical lung biopsy for the diagnosis of interstitial lung disease in England: 1997-2008. Eur Respir J 2016;48:1453-1461.
72 Lieberman S, Gleason JB, Ilyas MIM, Martinez F, Mehta JP, Savage EB: Assessing the safety and clinical impact of thoracoscopic lung biopsy in patients with interstitial lung disease. J Clin Diagn Res 2017;11:OC57OC59.

73 O’Donovan JP, Khan KA, Burke L, Murphy DM, Plant BP, Henry MT, Kennedy MP: Bronchoscopic cryobiopsy: initial experience in an interstitial lung disease centre. Irish J Med Sci 2014;183:11(suppl 1):S515-S516.

74 Sharp C, McCabe M, Adamali H, Medford AR: Use of transbronchial cryobiopsy in the diagnosis of interstitial lung disease-a systematic review and cost analysis. QJM 2017;110: 207-214.

75 Linhas R, Marçôa R, Oliveira A, Almeida J, Neves S, Campainha S: Transbronchial lung cryobiopsy: associated complications. Rev Port Pneumol (2006) 2017;23:331-337.

76 Chan JWM, Yeung YC, Sin KM, Lam DCL: Guidelines of procedural and sedation safety in flexible bronchoscopy and pleuroscopy. Hong Kong Thoracic Society, American College of Chest Physicians (Hong Kong and Macau Chapter), Hong Kong Lung Foundation, 2015.

77 Ernst A, Eberhardt R, Wahidi M, Becker HD, Herth FJ: Effect of routine clopidogrel use on bleeding complications after transbronchial biopsy in humans. Chest 2006;129:734-737.

78 Devarraj A, Wells AU, Meister MG, Corte TJ, Wort SJ, Hansell DM: Detection of pulmonary hypertension with multidetector $\mathrm{CT}$ and echocardiography alone and in combination. Radiology 2010;254:609-616.

79 Galiè N, Humbert M, Vachiery JL, et al: 2015 ESC/ERS guidelines for the diagnosis and treatment of pulmonary hypertension. The Joint Task Force for The diagnosis and Treatment of Pulmonary Hypertension of the European Society of Cardiology (ESC) and the European Respiratory Society (ERS): Endorsed by Association for European Paediatric and Congenital Cardiology (AEPC), International Society for Heart and Lung Transplantation (ISHLT). Eur Respir J 2015;46: 903-975.

80 Antoniou KM, Wells AU: Acute exacerbations of idiopathic pulmonary fibrosis. Respiration 2013;86:265-274.

81 Arcadu A, Moua T: Bronchoscopy assessment of acute respiratory failure in interstitial lung disease. Respirology 2017;22:352-359.

82 Harari S, Caminati A, Albera C, Vancheri C, Poletti V, Pesci A, Luppi F, Saltini C, Agostini C, Bargagli E, Sebastiani A, Sanduzzi A, Giunta V, Della Porta R, Bandelli GP, Puglisi S, Tomassetti S, Biffi A, Cerri S, Mari A, Cinetto F, Tirelli F, Farinelli G, Bocchino M, Specchia $\mathrm{C}$, Confalonieri M: Efficacy of pirfenidone for idiopathic pulmonary fibrosis: an Italian real life study. Respir Med 2015;109:904-913.
83 Martinez FJ, Flaherty KR: Comprehensive and Individualized patient care in idiopathic pulmonary fibrosis: refining approaches to diagnosis, prognosis, and treatment. Chest 2017;151:1173-1174

84 Lee SH, Shim HS, Cho SH, et al: Prognostic factors for idiopathic pulmonary fibrosis: clinical, physiologic, pathologic, and molecular aspects. Sarcoidosis Vasc Diffuse Lung Dis 2011;28:102-112.

85 Munoz Fernandez AM, Pajares V, Lucena C, Andreo F, Betbesé A, López L, Castro P, Badia JR, Ramírez J, Fabra M, Bonet G, Agustí C, Torrego A: Safety of transbronchial lung criobiopsy in mechanically ventilated patients in critical care. Multicenter study. European Respiratory Congress, 2016.

86 Sastre JA, Cordovilla R, Jimenez MF, Lopez T: Management of a transbronchial cryobiopsy using the i-gel ${ }^{\circledR}$ airway and the Arndt endobronchial blocker. Can J Anaesth 2014;61: 886-888.

87 Schmutz A, Durk T, Idzko M, Koehler T, Kalbhenn J, Loop T: Feasibility of a supraglottic airway device for transbronchial lung cryobiopsy. A retrospective analysis. J Cardiothorac Vasc Anesth 2017;31:1343-1347.

88 Gelzinis TA: Supraglottic airway device for transbronchial lung cryobiopsy. J Cardiothorac Vasc Anesth 2017;31:1348-1350.

89 Reif F: Simple applications of macroscopic thermodynamics; in Condon EU (ed): Mc Graw Hill Series: Fundamentals of Statistical and Thermal Physics. Colorado, Waveland Press 2008, pp 152-190.

90 Franke KJ, Linzenbold W, Nuessle D, Enderle M, Boesmueller H, Nilius G, Hetzel J: A new tool for transbronchial cryobiopsies in the lung: an experimental feasibility ex vivo study. Respiration 2016;91:228-234.

91 Yarmus LB, Semaan RW, Arias SA, FellerKopman D, Ortiz R, et al: A randomized controlled trial of a novel sheath cryoprobe for bronchoscopic lung biopsy in a porcine model. Chest 2016;150:329-336.

92 Cascante JA, Cebollero P, Herrero S, Yagüe A, Echegoyen A, Elizalde J, Hueto J: Transbronchial cryobiopsy in interstitial lung disease. Are we on the right path? J Bronchol Intervent Pulmonol 2016;23:204-209.

93 Lentz RJ, Argento AC, Colby TV, Rickman OB, Maldonado F: Tranbronchial cryobiopsy for diffuse parenchymal lung disease: a stateof-the-art review of procedural techniques, current evidence and future challenges. J Thorac Dis 2017;9:2186-2203.

94 Viglietta L, Inchingolo R, Pavano C, Tomassetti S, Piciucchi S, Smargiassi A, Ravaglia C, Dubini A, Gurioli C, Gurioli C, Poletti V: Ultrasonography for the diagnosis of pneumothorax after transbronchial lung cryobiopsy in diffuse cryobiopsy in diffuse parenchymal lung diseases. Respiration 2017;94:232-236. 